OPEN ACCESS

Edited by:

Muhammad Asif,

Wuhan Institute of Technology, China

Reviewed by:

Muhammad Ajmal,

Xiamen University, China

Hongwei Liu,

Sun Yat-sen University, China

${ }^{*}$ Correspondence:

Ayesha Aziz

anaa_meraal@yahoo.com

Shenqi Wang

shenqiwang131@hust.edu.cn

${ }^{\dagger}$ These authors have contributed

equally to this work

Specialty section: This article was submitted to

Analytical Chemistry,

a section of the journal

Frontiers in Chemistry

Received: 27 December 2021 Accepted: 17 January 2022

Published: 10 February 2022

Citation:

Wang H, Fan Y, Yang Q, Sun X, Liu H, Chen W, Aziz A and Wang S (2022)

Boosting the Electrochemical

Performance of PI-5-CA/C-SWCNT Nanohybrid for Sensitive Detection of

E. coli O157:H7 From the Real Sample.

Front. Chem. 10:843859.

doi: 10.3389/fchem.2022.843859

\section{Boosting the Electrochemical Performance of PI-5-CA/C-SWCNT Nanohybrid for Sensitive Detection of E. coli 0157:H7 From the Real Sample}

\author{
Huan Wang ${ }^{1 \dagger}$, Yanmiao Fan ${ }^{2 \dagger}$, Qiaoli Yang ${ }^{1}$, Xiaoyu Sun ${ }^{1}$, Hao Liu ${ }^{1}$, Wei Chen ${ }^{1}$, \\ Ayesha Aziz ${ }^{1 *}$ and Shenqi Wang ${ }^{1 *}$
}

${ }^{1}$ Advanced Biomaterials and Tissue Engineering Center, College of Life Science and Technology, Huazhong University of Life Science and Technology, Wuhan, China, ${ }^{2}$ School of Chemical Science and Engineering Fiber and Polymer Technology, KTH Royal Institute of Technology, Stockholm, Sweden

Redox activity is an important indicator for evaluating electrochemical biosensors. In this work, we have successfully polymerized indole-5-carboxylic acid into poly-5carboxyindole nanomaterials (PI-5-CA), using its superior redox activity, and introduced carboxylated single-walled carbon nanotubes (C-SWCNTs) to synthesize a composite material. Finally, a synthesized composite material was used for the modification of the glass carbon electrode to fabricate the PI-5-CA/C-SWCNTs/GCE-based immunosensor and was successfully applied for the sensitive detection of $E$. coli $\mathrm{O} 157: \mathrm{H} 7$. The fabricated immunosensor exhibited an outstanding electrocatalytic activity toward the detection of E. coli O157: $\mathrm{H} 7$ with a remarkably lowest limit of detection $(2.5 \mathrm{CFU} / \mathrm{ml}, L O D=3 \mathrm{SD} / \mathrm{k}, n=$ 3) and has a wide linear range from $2.98 \times 10^{1}$ to $2.98 \times 10^{7} \mathrm{CFU} / \mathrm{ml}$. Inspired from the excellent results, the fabricated electrode was applied for the detection of bacteria from real samples (water samples) with a good recovery rate (98.13-107.69\%) as well as an excellent stability and specificity. Owing to its simple preparation, excellent performance, and detection time within $30 \mathrm{~min}$, our proposed immunosensor will open a new horizon in different fields for the sensitive detection of bacteria from real samples.

Keywords: poly-5-carboxyindole, carboxylated single-walled carbon nanotubes, E. coli O157:H7, electrochemical immunosensor, indole-5-carboxylic acid, plate counting method

\section{HIGHLIGHTS}

- PI-5-CA/C-SWCNT nanohybrids are synthesized by facile methods

- The PI-5-CA/C-SWCNT nanohybrid-modified GCE was further incubated with the E. coli antibody to complete the antigen-antibody reaction to fabricate the Ab/PI-5-CA/C-SWCNTs/ GCE immunosensor

- Ab/PI-5-CA/C-SWCNTs/GCE shows an excellent electrochemical activity for E. coli O157 detection

- Real-time in vitro detection of E. coli O157 from real samples and compared results obtained from the actual samples 


\section{INTRODUCTION}

To date, the most important topic of concern for food industries is the alarming increase of food- and waterborne diseases (Law et al., 2015; Patra and Baek, 2016). According to statistics from the World Health Organization (WHO), up to $30 \%$ of the world's population suffers from foodborne diseases every year (Jia and Jukes, 2013). Factors that cause foodborne diseases include bacteria, parasites, viruses, chemicals, and toxins (Aziz et al., 2021; Rad et al., 2021). Among these factors, bacterial contamination is an alarming threat to human health (Chen et al., 2017; Sai-Anand et al., 2019). Bacteria are ubiquitous in nature, and bacterial contamination may occur in any food chain (Odeyemi et al., 2020). If food chains once get infected with these pathogens, it can seriously threaten human health and can cause economic losses, if not treated timely (Asif et al., 2018). In 2011, there was an outbreak in the United States due to the contamination of cantaloupe instigated by Listeria monocytogenes, which infected 147 with 33 deaths (Ghosh et al., 2019). In the same year, Germany also experienced a massive outbreak of hemolytic uremic syndrome, which was initiated by E. coli O104:H4 infection (Stockman, 2013). Above all, every year, the number of infections caused by Salmonella crossed one million, leading to severe illness and sometimes death (Jarvis et al., 2016). In 2016, 13 cases of diarrhea occurred in nine U.S. states due to the consumption of flour infected with E. coli O157:H7 (Sperber and North American Millers' Association Microbiology Working Group, 2007). Therefore, fast and reliable detection of pathogens is essential to prevent and control the outbreaks of foodborne diseases.

Among the common pathogens in daily life, E. coli O157:H7 is one of the most hazardous foodborne pathogens because of its virulence and pathogenicity (Buchanan and Doyle, 1997; Zhao et al., 2021). Diseases caused by E. coli O157:H7 include diarrhea, fever, and vomiting (Pandey et al., 2017). At present, quite a lot of attention has been devoted to the research for the rapid detection of E. coli O157:H7 (Park et al., 2020) The conventionally used plate counting method is reliable to some extent but inevitably limited owing to the time-consumption (Sieuwerts et al., 2008; Zhao et al., 2014). Technological advances introduced and proposed new methods and techniques, such as polymerase chain reaction (PCR) (Amagliani et al., 2004; Zhou et al., 2022) and enzyme-linked immunosorbent assay (ELISA) (Di Febo et al., 2019; Hu Y. et al., 2021), but the requirement of high precision and accuracy as well as the need of highly professional trainers limited their use to some extent. To address all these issues related to conventional and advanced techniques, biosensors have been developed (Aziz et al., 2022). The development of biosensors can solve the abovementioned problems (Asif et al., 2019; Aziz et al., 2019b), such as colorimetry (Yao et al., 2020), fluorescence (Shi et al., 2015), and electrochemistry (Li et al., 2021). Among them, the electrochemical method has received widespread attention because of the low cost, easy handling, and portability (Asif et al., 2022).

Many electrochemical redox active materials have been used as electronic media for the development of electrochemical biosensors, such as ferrocene (Hu L. et al., 2021), graphene oxide (GO) (Aziz et al., 2019a), and Prussian blue (22). However, most of these materials suffer low conductivity and poor stability, so their effects in the field of electrochemical detection are not satisfactory (Kang et al., 2016). As a conductive polymer, poly (indole-5-carboxylic acid) (PI-5-CA) exhibits good electrochemical behavior, good thermal stability, and superior redox activity due to its abundant functional groups and specific surface area (Asif et al., 2015; Yang et al., 2019). At the same time, the introduction of carboxylated single-walled carbon nanotubes (C-SWCNTs) can further improve the specific surface area and the electrical conductivity of PI-5-CA. Due to its tubular hollow structure, carbon nanotubes have unique electrical conductivity, high strength, flexibility, stable chemical properties, and excellent specific surface area (Kumar and Sundramoorthy, 2019; Li et al., 2021). Through chemical synthesis, PI-5-CA and C-SWCNTs are synthesized into a composite material to syndicate the electrochemical advantages of the two, and using their abundant carboxyl functional groups to combine with various biological recognition molecules (Yang et al., 2019).

Therefore, we use the superior electrical conductivity of C-SWCNTs and the ultrahigh redox activity of PI-5-CA to construct an electrochemical sensing platform (Joshi and Prakash, 2013; Yang et al., 2019). At the same time, we use the characteristic of antigen-antibody-specific binding to propose an electrochemical immunosensor to detect $E$. coli O157:H7. First, the PI-5-CA/C-SWCNT composite material was synthesized for the modification of glassy carbon electrode (GCE), and the redox characteristics of the material were explored using the classic three-electrode system. By activating the carboxyl group on the surface of the material and binding with the amino group of the antibody, the anti- $E$. coli antibody is connected to the surface of the modified GCE for E. coli $\mathrm{O} 157: \mathrm{H7}$ detection as represented by Figure 1. In this research work, PI-5-CA was used to provide a stable redox signal to improve the detection sensitivity (Joshi and Prakash, 2013), while C-SWCNT coupling was used to further improve stability and conductivity (Joshi and Prakash, 2013), as well as provide abundant binding sites for antibodies, which in turn ensure the detection specificity. By detecting the change of PI-5CA redox current, the rapid and sensitive detection effect of E. coli O157:H7 is realized (Yang et al., 2021). We used this constructed biosensor to successfully detect $E$. coli in domestic water, and compared the results with the traditional culture method to determine the sensitivity and reliability of the fabricated sensor.

\section{EXPERIMENTAL SECTIONS}

\subsection{Chemicals and Reagents}

Indole-5-carboxylic acid (I-5-CA) was purchased from Shanghai Vita Chemical Regent Co., Ltd. (Shanghai, China). Carboxylated single-walled carbon nanotubes (C-SWCNTs) were purchased from Nanjing Xian Feng Nanomaterials Technology Co., Ltd. (Nanjing, China). N-hydroxysuccinimide (NHS) and $\mathrm{N}-(3-$ dimethylaminopropyl)- $\mathrm{N}^{\prime}$-ethylcarbodiimide hydrochloride 


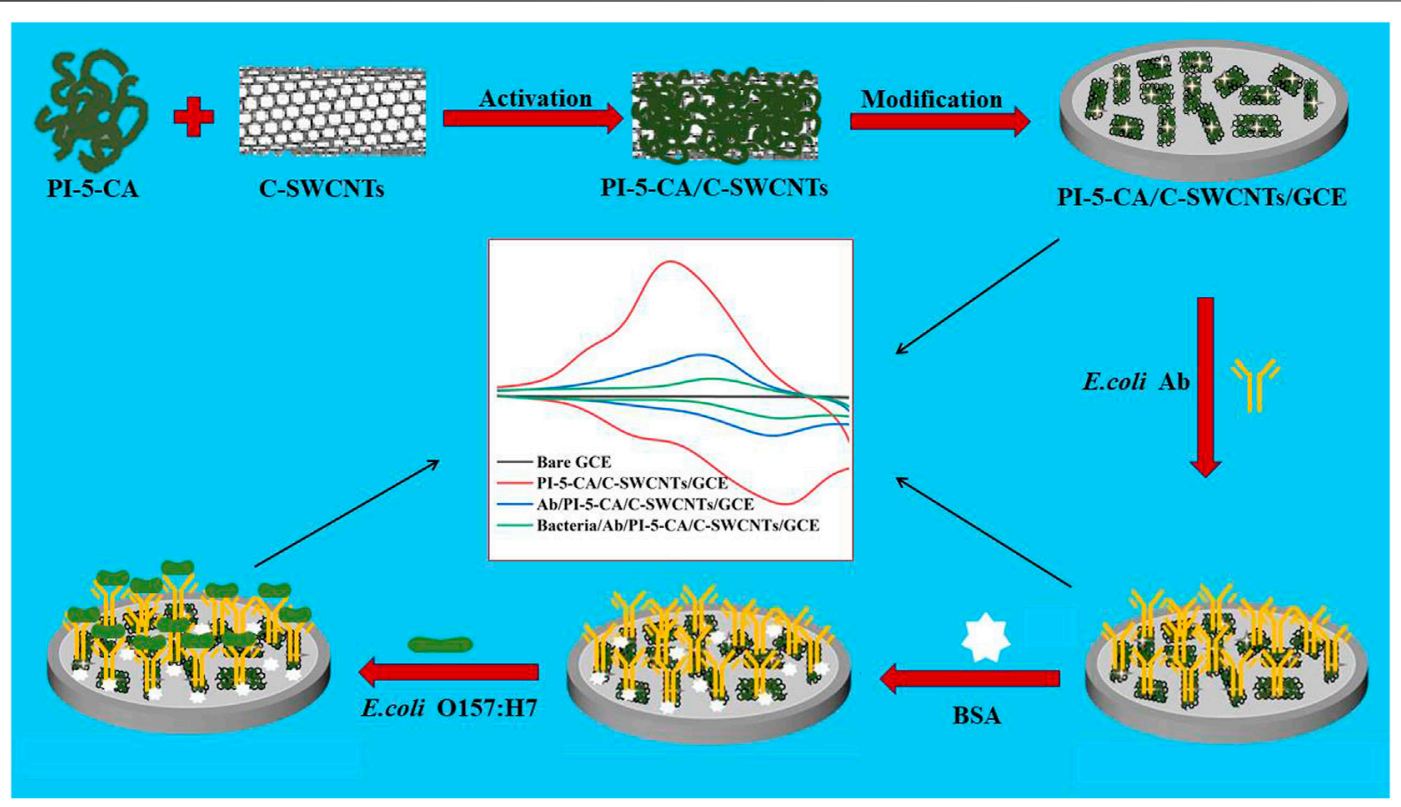

FIGURE 1 | Schematic illustration of the step-by-step preparation of PI-5-CA/C-SWCNTS/GCE and its modification with antibodies and BSA for the sensitive detection of E. coli O157: $\mathrm{H7}$.

TABLE 1 | Information of the strains used in this work.

\begin{tabular}{ll}
\hline Bacteria & \multicolumn{1}{c}{ Strain number } \\
\hline E. coli O157:H7 & CCTCC AB 200051 \\
Staphylococcus aureus & CCTCC AB 2013186 \\
Salmonella typhimurium & CCTCC AB 204062 \\
Pseudomonas aeruginosa & ATCC27853
\end{tabular}

(EDC) were purchased from Aladdin Chemistry Co., Ltd. (Shanghai, China). Bovine serum albumin (BSA) and 2morpholinoethanesulfonic acid (MES) were purchased from Sigma-Aldrich (United States). The anti-E. coli O157:H7 antibody was purchased from Thermo (United States). Ethanol, ammonium persulfate (APS), disodium hydrogen phosphate $\left(\mathrm{Na}_{2} \mathrm{HPO}_{4}\right)$, sodium dihydrogen phosphate $\left(\mathrm{NaH}_{2} \mathrm{PO}_{4}\right)$, and $\mathrm{H}_{2} \mathrm{SO}_{4}$ were purchased from Sinopharm Chemical Co., Ltd. (Shanghai, China). All the chemicals and reagents were used as it is, without further purification. The four different strains were used in this research as shown in Table 1.

\subsection{Synthesis of PI-5-CA/C-SWCNTs}

The PI-5-CA/C-SWCNT nanocomposite was synthesized by the chemical method. First, $100 \mathrm{mg}$ of In-5-COOH monomer and $2 \mathrm{mg}$ of carboxylated single-walled carbon nanotubes (C-SWCNTs) were dissolved in $2.5 \mathrm{ml}$ of absolute ethanol, Next, $100 \mathrm{mg}$ ammonium persulfate (APS) was dissolved in $10.0 \mathrm{ml}$ of $\mathrm{H}_{2} \mathrm{SO}_{4}(\mathrm{pH}=1)$. Under constant temperature stirring, the mixed solution of $100 \mathrm{mg}$ ammonium persulfate (APS) dissolved in $10 \mathrm{ml} \mathrm{H}_{2} \mathrm{SO}_{4}(\mathrm{pH}=1)$ was added gradually, and the mixture was left to react at $30^{\circ} \mathrm{C}$ for $6 \mathrm{~h}$. After the reaction was completed, the product was filtered and washed with ultrapure water and absolute ethanol several times in sequence. Finally, we used this solid product to prepare $1 \mathrm{mg} /$ $\mathrm{ml}$ solution in ultrapure water for further use.

\subsection{Fabrication of the Electrochemical Immunosensor}

Before each experiment, the glassy carbon electrode $(3 \mathrm{~mm}$ in diameter) was polished to a mirror surface with $0.05 \mu \mathrm{M}$ alumina powder and ultrasonically treated with ultrapure water and absolute ethanol, respectively. Finally, the cleaned electrode was dried with high-purity nitrogen for the next modification.

For the modification of electrode, $10 \mu \mathrm{L}$ of $1 \mathrm{mg} / \mathrm{ml}$ solution of PI-5-CA/C-SWCNTs was injected onto the surface of the GCE and dried in air naturally. To activate the carboxyl group on the composite material, first, the modified electrode was immersed in a mixed solution (containing $40 \mathrm{mM}$ NHS, $100 \mathrm{mM}$ EDC and $100 \mathrm{mM}$ MES), and then incubated at $37^{\circ} \mathrm{C}$ for $30 \mathrm{~min}$ accompanied by the subsequent deposition of $10 \mu \mathrm{L}$ of Ab solution $(5 \mu \mathrm{g} / \mathrm{ml})$. After that the prepared Ab/PI-5-CA/C-SWCNTs/GCE was further incubated at $37^{\circ} \mathrm{C}$ for $2 \mathrm{~h}$ to ensure that the antibodies bind to the electrode surface. Next, $10 \mu \mathrm{L}$ of BSA $(1 \mathrm{mg} / \mathrm{ml})$ was added dropwise onto the electrode surface and incubated at $37^{\circ} \mathrm{C}$ for 30 min to block the residual active sites. Finally, the prepared immunosensor was successfully used against bacterial detection and repeated the same procedure after each experiment. It is noted that after each modification, the electrode should be gently washed with $\mathrm{PBS}(\mathrm{pH}=6)$ to remove physical adsorption (26). 
A

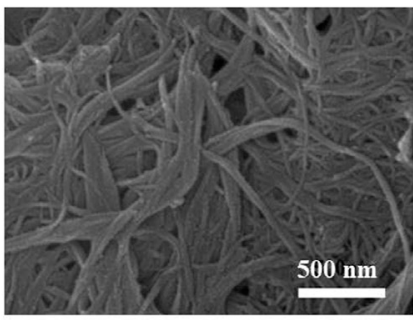

D

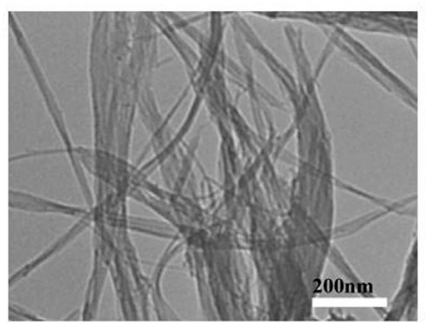

B

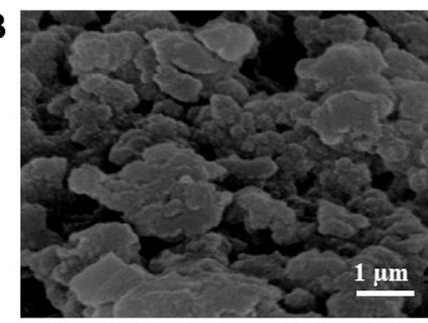

E

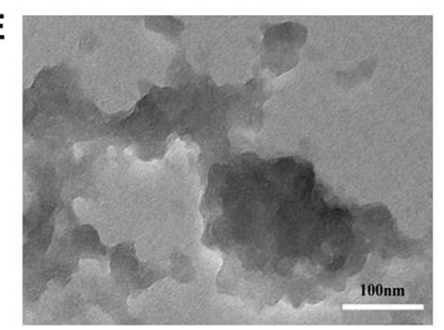

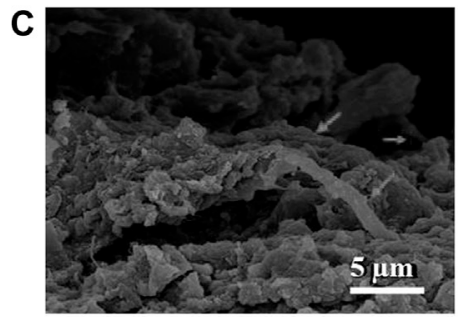

$\mathbf{F}$

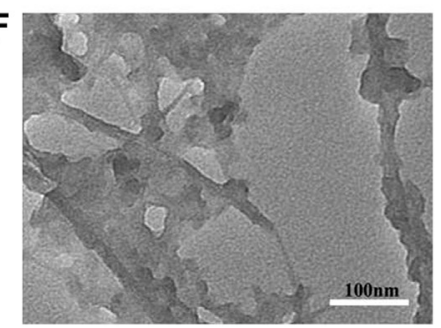

FIGURE 2 | (A-C) SEM images of C-SWCNTs, PI-5-CA, and PI-5-CA/C-SWCNTs at different magnifications, and TEM images of (D) C-SWCNTs, (E) PI-5-CA, and (F) PI-5-CAVC-SWCNTS.

\subsection{Preparation of Samples}

In order to obtain satisfactory results, pretreatment of the bacterial culture medium is necessary. The bacterial strains used in the research were inoculated into the $5 \mathrm{ml} \mathrm{LB}$ medium and cultured at $37^{\circ} \mathrm{C}$ and $200 \mathrm{rpm}$ for $6 \mathrm{~h}$ to their logarithmic growth phase. After that, the freshly cultivated bacterial liquids were centrifuged and immersed in PBS to further dilute into appropriate concentrations. The sample preparation process for actual testing is as follows: first, the tap water was filtered three times with a $0.22 \mu \mathrm{M}$ filter membrane, and then freshly cultured E. coli O157:H7 was added to obtain a natural sample.

\subsection{Analytical Performance of the Immunosensor}

First, $10 \mu \mathrm{L}$ of the above bacterial liquid was injected to the surface of the immunosensor electrode, and it was incubated at $37^{\circ} \mathrm{C}$ for $2 \mathrm{~h}$ to complete the antigen-antibody reaction. After that, the electrode was gently washed with PBS $(\mathrm{pH}=6)$ to remove the physical absorption. All electrochemical experiments were performed on a CHI660A electrochemical workstation. Throughout the electrochemical experimentation, a threeelectrode system $(\mathrm{Ag} / \mathrm{AgCl}$ as the reference electrode, platinum plate as the counter electrode, and modified electrode as the working electrode) was used to perform cyclic voltammetry (CV) under $-0.2-0.8 \mathrm{~V}$ at a scanning speed of $100 \mathrm{mV} / \mathrm{s}$ to evaluate the electrode surface behavior. Throughout the experimentations, PBS ( $\mathrm{pH}=6)$ was used.

\section{CHARACTERIZATION OF THE PI-5-CA/ C-SWCNTS COMPOSITE}

The surface morphologies of PI-5-CA and C-SWCNTs were initially characterized by using the transmission electron microscope (TEM) and scanning electron microscope (SEM) to observe the morphology of the three-dimensional structure of PI-5-CA/C-SWCNTs. The SEM images of PI-5-CA/ C-SWCNT nanocomposite at different magnifications showed in Figures 2A-C formed a three-dimensional layered porous structure, which can facilitate the combination of various biorecognition molecules and improve the analytical performance of the electrochemical sensor based on PI-5-CA/ C-SWCNTs. PI-5-CA exhibited a distinct aggregated morphology that was further combined with SWCNTs to form a distinct three-dimensional structure. SWCNT rods covered with aggregated PI-5-CA as rough surfaces greatly enhance the surface area to provide more active sites to complete the catalytic reaction. SWCNTs support completely burying inside PI-5-CA enhances the catalytic efficiency of the fabricated material being conductive materials. The SEM image results are also consistent with the TEM results taken at different magnification as shown in Figures 2D-F.

The polymerization mechanism of PI-5-CA was studied by Fourier transform infrared spectroscopy (FT-IR), and the result is shown in Figure 3A. The spectral absorption peak intensity of PI-5CA is significantly wider than that of I-5-CA monomer, which may be attributable to the wide conjugated chain length distribution of polymers (Liu et al., 2016; Yang et al., 2021). Among them, in the spectrum of monomer I-5-CA and polymer PI-5-CA, the fluctuation of absorption peak in the range of $700-820 \mathrm{~cm}^{-1}$ is caused by the deformation vibration of three $\mathrm{C}-\mathrm{H}$ on the benzene ring, which indicates that the polymerization of monomer occurs on the pyrrole ring (Sivakkumar et al., 2005). The $=\mathrm{CH}-\mathrm{N}$ stretching vibration of the monomer near $890 \mathrm{~cm}^{-1}$ disappeared in the polymer spectrum. The peaks near $1,478-1,838 \mathrm{~cm}^{-1}$ showed the presence of carboxyl groups in the monomer I-5-CA and the polymer PI-5-CA (Narang et al., 2013). Compared with the FT-IR spectra of PI-5-CA, the FTIR spectra of PI-5-CA/C-SWCNT nanocomposites showed a onepoint positive shift in the $\mathrm{C}=\mathrm{C}$ bond, which should be attributed to 

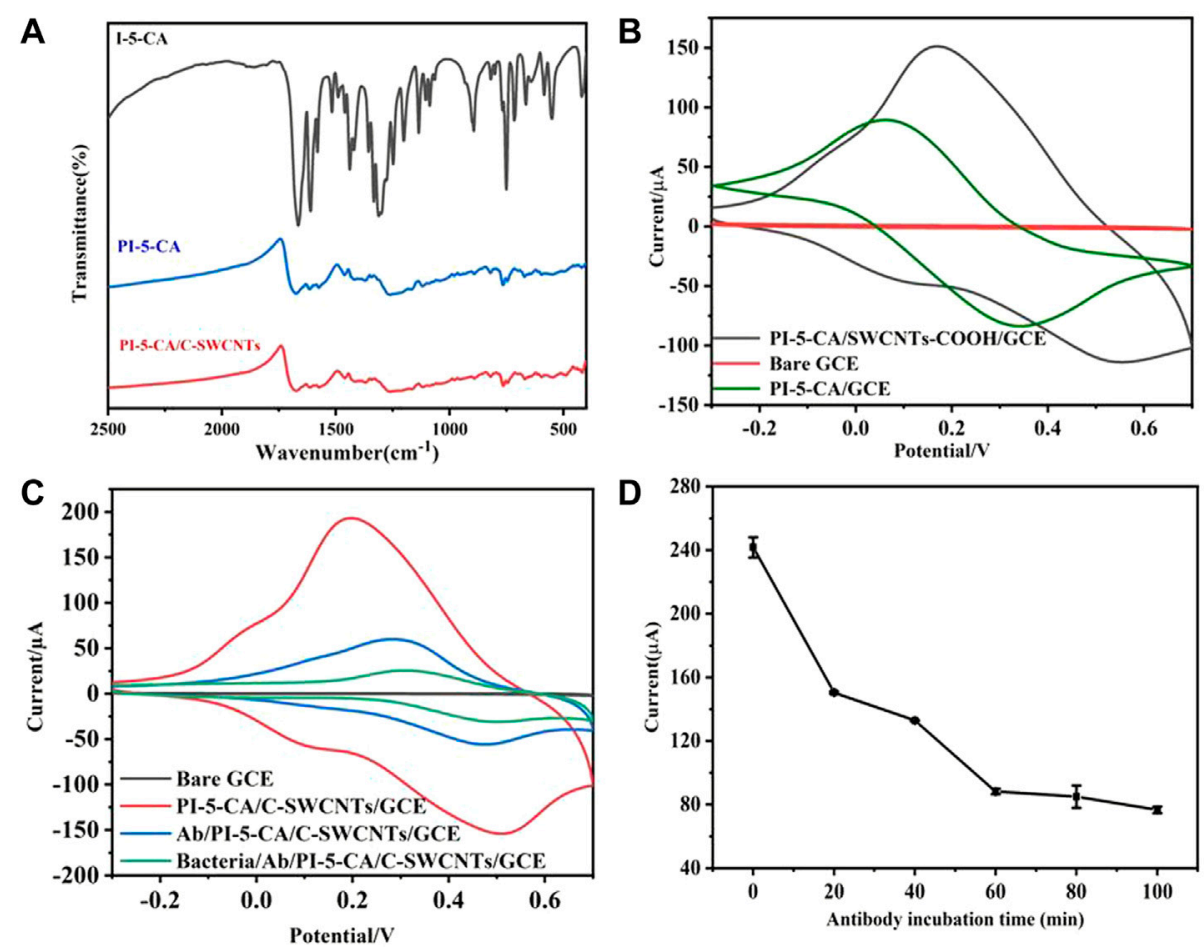

FIGURE 3 | (A) FT-IR characterization results of I-5-CA, PI-5-CA, and PI-5-CAVC-SWCNTs. (B) CV of electrodes modified with PI-5-CAVC-SWCNTs, bare GC, and $\mathrm{Pl}-5-\mathrm{CA}$ in $0.1 \mathrm{M}$ PBS (pH = 6). (C) CV representation of the electrode in $0.1 \mathrm{M} \mathrm{PBS}(\mathrm{pH}=6)$ after each step of modification, and (D) the current changes of the immunosensor under different antibody incubation times in $0.1 \mathrm{M} \mathrm{PBS}(\mathrm{pH}=6)$.

the $\pi-\pi$ interaction between PI-5-CA and C-SWCNTs (Yang et al., 2019).

\section{RESULTS AND DISCUSSION}

\subsection{Electrochemical Performance of PI-5-CA/C-SWCNTs/GCE}

Compared with the bare GCE, both PI-5-CA/C-SWCNTs and PI5-CA-modified electrodes can promote electron transfer and generate redox current. It can be seen from Figure 3B that the redox current peak value of PI-5-CA/C-SWCNTs/GCE is significantly higher than that of PI-5-CA/GCE, which may be attributed to the tubular structure of C-SWCNTs promoting the electron transfer of PI-5-CA. Figure 3C shows the electron transfer behavior of the electrode surface after each modification. Because PI-5-CA/C-SWCNTs have higher redox activity and conductivity, a higher redox current peak can be clearly seen. In that case, when antibodies bound to the carboxyl groups present on the surface of PI-5-CA/C-SWCNTs, a reduction in the peak redox current can be clearly observed. This is due to the fact that the antibody protein is a nonconductive substance, which causes hindrance during the electron transfer on the electrode surface that resultantly causes a decrease in redox current. After incubating with E. coli $\mathrm{O} 157: \mathrm{H} 7$ bacterial solution, the peak redox current further decreased, which just proved that the bacterial solution successfully combined with the antibody on the electrode surface. This reduction was due to the increased steric effect of antigen-antibody immune complexes during electron transfer. The current change on the surface of the glassy carbon electrode indicates the successful preparation of the immunosensor, which can be further used as a potential platform for detecting bacteria.

\subsection{Optimization of Experimental Parameters}

\subsubsection{Optimization of Antibody Incubation Time}

When the PI-5-CA/C-SWCNT composite material was deposited on the surface of the electrode, the carboxyl group can be activated with a mixed solution containing EDC, NHS, and MES. Then, $10 \mu \mathrm{L}$ of antibody solution was dropped onto the surface of the electrode, which helps antibodies to get attached to the surface of the GCE through the amino-carboxyl reaction in a $37^{\circ} \mathrm{C}$ water bath. In order to make sure the $-\mathrm{COOH}$ group of the $\mathrm{PI}-5-\mathrm{CA} /$ C-SWCNT composite material can bind to more and more antibodies, the incubation time was optimized within $100 \mathrm{~min}$.

It can be seen from Figure 3D that as the incubation time increases, the peak value of the redox current on the electrode surface gradually decreases. This is due to the gradual increase in the amount of antibodies bound to the electrode surface, which increases the impedance of electron transfer. As shown in Figure 3D, after about $60 \mathrm{~min}$ of reaction, the current peak 

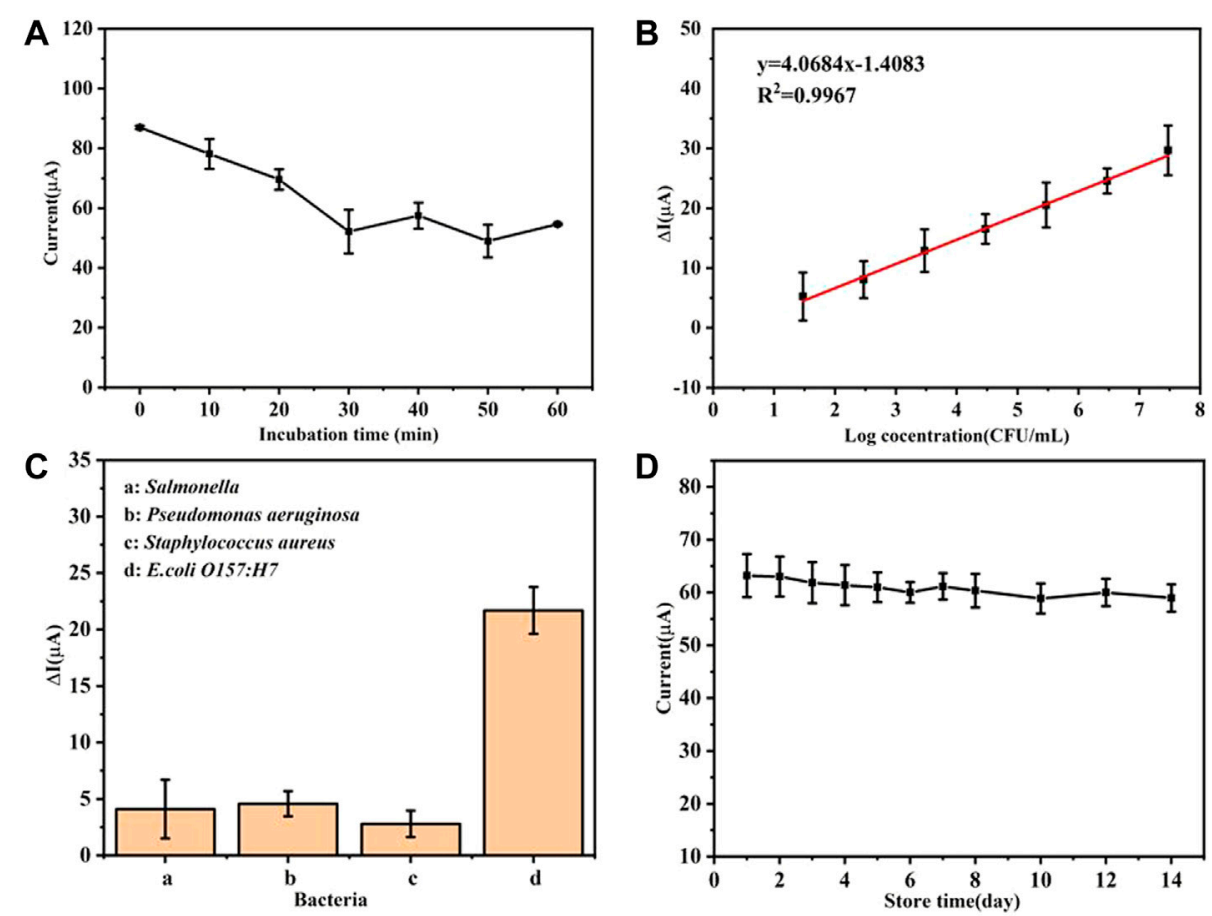

FIGURE 4 | (A) Current changes of the immunosensor under different bacterial incubation times, (B) linear relationship between the current change value and the logarithm of the bacterial concentration, (C) detection specificity of the immunosensor, and (D) performance of the electrochemical immunosensors at various storage periods.

gradually stabilized. It can be concluded that the antibodies bound to the electrode surface reach a relatively saturated state after $60 \mathrm{~min}$ of incubation. Later studies also chose $60 \mathrm{~min}$ as the antibody incubation time.

\subsubsection{Optimization of Incubation Time for E. coli O157:H7}

In order to ensure the binding of sufficient amount of bacteria on the electrode to achieve a sensitive detection effect, the incubation time of the bacteria solution was further optimized. The freshly cultured E. coli O157:H7 bacterial solution was immersed in PBS after centrifugation, and then was diluted to different concentrations. In total, $10 \mu \mathrm{L}$ of $4 \times 10^{6} \mathrm{CFU} / \mathrm{mL}$ E. coli O157:H7 bacterial liquid was added dropwise to the prepared immunosensing electrode and incubated at $37^{\circ} \mathrm{C}$ for different times.

As the incubation time increases, the oxidation peak current gradually decreases and the current value tends to stabilize at about $30 \mathrm{~min}$ as depicted by Figure 4A. In the subsequent incubation time, the fluctuation of the current value may be attributed to the reversibility of the antigen-antibody immune binding reaction (Ghosh, 2006). In summary, $30 \mathrm{~min}$ was selected as the reaction time for the combination of bacteria and immunosensor.

\subsection{Analytical Performance of the Immunosensor}

Under the optimal experimental conditions, the analytical performance of the prepared immunosensor was studied. The
E. coli $\mathrm{O} 157: \mathrm{H} 7$ monoclonal colony was picked into the LB liquid medium and cultivated to a logarithmic phase at $37^{\circ} \mathrm{C}$ with $200 \mathrm{rpm}$ shaking. Later, the freshly cultured bacterial solution was centrifuged and immersed in PBS. Finally, the bacterial liquid was diluted to a series of concentration gradient from $2.98 \times 10^{1}$ to $2.98 \times 10^{7} \mathrm{CFU} / \mathrm{ml}$, and $10 \mu \mathrm{L}$ of the abovementioned diluted bacterial solution was dropped onto the electrode surface and incubated for $30 \mathrm{~min}$ in a $37^{\circ} \mathrm{C}$ water bath. After that, the current changes on the electrode surface were recorded.

It can be seen from Figure $\mathbf{4 B}$ that there is a good linear relationship between the current change value $(\Delta \mathrm{I})$ (before and after the immunosensor is combined with the bacterial solution) and the logarithmic value of the bacterial solution concentration $[\log (\mathrm{CFU} / \mathrm{ml})]$. After fitting, within the linear range, the linear relationship between $\Delta \mathrm{I}$ and the concentration of $E$. coli $\mathrm{O} 157: \mathrm{H} 7$ is $\Delta \mathrm{I}=4.0684 \log (\mathrm{CFU} / \mathrm{mL})-1.4083\left(R^{2}=0.9976\right)$ with a low limit of detection of $2.5 \mathrm{CFU} / \mathrm{ml}(L O D=3 \mathrm{SD} / \mathrm{k}, n=3)$. It can be concluded that the prepared immunosensor platform has great potential for the rapid detection of E. coli O157:H7, which can provide a basis for the next step of detection in natural samples.

\subsection{Analytical Specificity of the Immunosensor}

In order to explore specificity of the biosensing system for E. coli O157:H7 detection, different types of strains such as Salmonella, Pseudomonas aeruginosa, Staphylococcus aureus, and E. coli O157: $\mathrm{H} 7$ have been detected by repeating the same detection procedure. In 
TABLE 2 | Assay results of the actual sample using the proposed and plate counting method.

\begin{tabular}{lcclcc}
\hline \multirow{2}{*}{ Added (CFU/mL) } & \multicolumn{2}{c}{ Detected $(\mathbf{C F U} / \mathrm{mL})$} & & \multicolumn{2}{c}{ Recovery (\%) } \\
\cline { 2 - 3 } \cline { 5 - 6 } \cline { 5 - 6 } & Biosensor & Plate count & & Biosensor & Plate count \\
\hline $1.04 \times 10^{2}$ & $1.12 \times 10^{2}$ & $1.08 \times 10^{2}$ & & 107.69 & 103.85 \\
$3.2 \times 102$ & $3.21 \times 102$ & $3.43 \times 102$ & & 100.31 & 107.19 \\
$3.2 \times 10^{4}$ & $3.14 \times 10^{4}$ & $3.16 \times 10^{4}$ & & 98.13 & 98.75 \\
$3.2 \times 10^{6}$ & $3.32 \times 10^{6}$ & $3.19 \times 10^{6}$ & & 103.75 & 99.69 \\
\hline
\end{tabular}

total, $10 \mu \mathrm{L}$ of $10^{6} \mathrm{CFU} / \mathrm{ml}$ of the aforementioned various fresh bacterial liquids were injected onto the prepared immune-electrode surface, respectively, for the sensitive strain detection.

In comparison to the E. coli O157:H7 modified immunosensor, the other immunosensors modified with Salmonella, Pseudomonas aeruginosa, and Staphylococcus aureus exhibited up to 20\% less response toward the target strain as shown in Figure 4C. It can be seen that the specificity of the developed electrochemical immunosensor is acceptable.

\subsection{Stability of the Immunosensor}

The storage performance of this sensor also was studied. The prepared antibody sensor was stored at $4^{\circ} \mathrm{C}$ and the peak value of the redox current on the electrodes was detected every other day. It can be seen from Figure 4D that the prepared immunosensor has good storage stability. After 1 week, it can still maintain $96.78 \%$ of the original current value. After 2 weeks of storage, the current value was about $93.30 \%$ of the original value, which further shows that the sensor has good stability and practical applications potential.

\subsection{Detection and Analysis of Real Samples}

Benefitted from the excellent electrochemical performance, we applied our modified electrode for the detection of E. coli O157: H7 from the real samples and compared the results obtained from the actual samples with the plate counting method in Table 2.

Recovery (\%) is expressed as the ratio of the number of detected/number of spiked. As shown in Table 2, the recovery rate of the prepared biosensor is $98.13-107.69 \%$, indicating that the proposed immunosensor for E. coli O157:H7 detection has good accuracy. In other words, this electrochemical immunosensor provides a potential application prospect for the analysis of E. coli O157:H7 in natural samples.

\section{CONCLUSION}

In summary, we have successfully proposed a PI-5-CA/ C-SWCNT-based electrochemical immunosensor for the rapid

\section{REFERENCES}

Amagliani, G., Brandi, G., Omiccioli, E., Casiere, A., Bruce, I. J., and Magnani, M. (2004). Direct Detection of Listeria Monocytogenes from Milk by Magnetic Based DNA Isolation and PCR. Food Microbiol. 21 (5), 597-603. doi:10.1016/j. fm.2003.10.008 detection of E. coli O157:H7. First, we prepared PI-5-CA/ C-SWCNT composites with a three-dimensional porous structure through a simple chemical oxidation polymerization method. The PI-5-CA/C-SWCNT material has a stable redox activity, good conductivity, large specific surface area, and abundant functional groups. By taking the advantage of these superb characteristics, we used antibodies as biorecognition molecules to construct Ab/PI-5-CA/C-SWCNTs/GCE immunosensing electrodes for the sensitive detection of E. coli O157:H7. Compared with previous reported works (Xue et al., 2020; Yang et al., 2020; Qaanei et al., 2021), our fabricated biosensor can detect bacteria as low as $29.8 \mathrm{CFU} / \mathrm{ml}$ within $30 \mathrm{~min}$, which greatly shorten the detection time. At the same time, the immunosensor shows good sensitivity, specificity, reproducibility, and stability toward the detection of $E$. coli O157:H7. We believe that the bacteria detection method proposed in this article has good application prospects, which can not only be used for the sensitive and selective detection of E. coli O157:H7 but also pave a way for the simple and fast detection of different bacterial strains as well as other substances.

\section{DATA AVAILABILITY STATEMENT}

The original contributions presented in the study are included in the article/Supplementary Material; further inquiries can be directed to the corresponding authors.

\section{AUTHOR CONTRIBUTIONS}

HW conceived the idea, carried out the whole experimental work, and wrote the manuscript. YF contributed in conceiving the idea and helped in revising the manuscript. QY helped in revision. XS helped in experiments. HL contributed in arranging bacteria. WC helped in experiments and removed typo mistakes. AA helped in visualization, writing-original draft, and revision. SW helped in different aspects, funding acquisition, conceptualization, visualization, writing-original draft, and revision.

\section{FUNDING}

This research work was funded by the National Key Research and Development Program of China under Grant 2017YFC1104402, the China Postdoctoral Science Foundation (2016M602291), the initial research fund from Chinese Scholarship Council (CSC), and 3551 Project, Optics Valley of China.

Asif, M., Aziz, A., Dao, A. Q., Hakeem, A., Wang, H., Dong, S., et al. (2015). Real-Time Tracking of Hydrogen Peroxide Secreted by Live Cells Using $\mathrm{MnO} 2$ Nanoparticles Intercalated Layered Doubled Hydroxide Nanohybrids. Analytica Chim. Acta 898, 34-41. doi:10.1016/j.aca.2015. 09.053

Asif, M., Aziz, A., Azeem, M., Wang, Z., Ashraf, G., Xiao, F., et al. (2018). A Review on Electrochemical Biosensing Platform Based on Layered Double Hydroxides 
for Small Molecule Biomarkers Determination. Adv. Colloid Interf. Sci. 262, 21-38. doi:10.1016/j.cis.2018.11.001

Asif, M., Aziz, A., Wang, H., Wang, Z., Wang, W., Ajmal, M., et al. (2019). Superlattice Stacking by Hybridizing Layered Double Hydroxide Nanosheets with Layers of Reduced Graphene Oxide for Electrochemical Simultaneous Determination of Dopamine, Uric Acid and Ascorbic Acid. Microchim Acta 186 (2), 61. doi:10.1007/s00604-018-3158-y

Asif, M., Aziz, A., Ashraf, G., Iftikhar, T., Sun, Y., Xiao, F., et al. (2022). Unveiling Microbiologically Influenced Corrosion Engineering to Transfigure Damages into Benefits: A Textile Sensor for $\mathrm{H} 2 \mathrm{O} 2$ Detection in Clinical Cancer Tissues. Chem. Eng. J. 427, 131398. doi:10.1016/j.cej.2021.131398

Aziz, A., Asif, M., Ashraf, G., Azeem, M., Majeed, I., Ajmal, M., et al. (2019a). Advancements in Electrochemical Sensing of Hydrogen Peroxide, Glucose and Dopamine by Using 2D Nanoarchitectures of Layered Double Hydroxides or Metal Dichalcogenides. A Review. Microchim Acta 186 (10), 671. doi:10.1007/ s00604-019-3776-z

Aziz, A., Asif, M., Azeem, M., Ashraf, G., Wang, Z., Xiao, F., et al. (2019b). SelfStacking of Exfoliated Charged Nanosheets of LDHs and Graphene as Biosensor with Real-Time Tracking of Dopamine from Live Cells. Analytica Chim. Acta 1047, 197-207. doi:10.1016/j.aca.2018.10.008

Aziz, A., Asif, M., Ashraf, G., Farooq, U., Yang, Q., and Wang, S. (2021). Trends in Biosensing Platforms for SARS-CoV-2 Detection: A Critical Appraisal against Standard Detection Tools. Curr. Opin. Colloid Interf. Sci 52, 101418. doi:10. 1016/j.cocis.2021.101418

Aziz, A., Asif, M., Ashraf, G., Iftikhar, T., Hu, J., Xiao, F., et al. (2022). Boosting Electrocatalytic Activity of Carbon Fiber@fusiform-Like Copper-Nickel LDHs: Sensing of Nitrate as Biomarker for NOB Detection. J. Hazard. Mater. 422, 126907. doi:10.1016/j.jhazmat.2021.126907

Buchanan, R. L., and Doyle, M. P. (1997). Foodborne Disease Significance of Escherichia C O157: H7 and Other Enterohemorrhagic E. C. Food Technol. (Chicago) 51 (10), 69-76.

Chen, J., Andler, S. M., Goddard, J. M., Nugen, S. R., and Rotello, V. M. (2017). Integrating Recognition Elements with Nanomaterials for Bacteria Sensing. Chem. Soc. Rev. 46 (5), 1272-1283. doi:10.1039/c6cs00313c

Di Febo, T., Schirone, M., Visciano, P., Portanti, O., Armillotta, G., Persiani, T., et al. (2019). Development of a Capture ELISA for Rapid Detection of Salmonella E in Food Samples. Food Anal. Methods 12 (2), 322-330. doi:10. 1007/s12161-018-1363-2

Ghosh, P., Zhou, Y., Richardson, Q., and Higgins, D. E. (2019). Characterization of the Pathogenesis and Immune Response to Listeria Monocytogenes Strains Isolated from a Sustained National Outbreak. Sci. Rep. 9 (1), 19587. doi:10. 1038/s41598-019-56028-3

Ghosh, R. (2006). Membrane Chromatographic Immunoassay Method for Rapid Quantitative Analysis of Specific Serum Antibodies. Biotechnol. Bioeng. 93 (2), 280-285. doi:10.1002/bit.20707

Hu, L., Gong, B., Jiang, N., Li, Y., and Wu, Y. (2021a). Electrochemical Biosensor for Cytokinins Based on the CHASE Domain of Arabidopsis Histidine Kinases 4. Bioelectrochemistry 141, 107872. doi:10.1016/j.bioelechem.2021.107872

Hu, Y., Sun, Y., Gu, J., Yang, F., Wu, S., Zhang, C., et al. (2021b). Selection of Specific Nanobodies to Develop an Immuno-Assay Detecting Staphylococcus A in Milk. Food Chem. 353, 129481. doi:10.1016/j.foodchem.2021.129481

Jarvis, N. A., O’Bryan, C. A., Dawoud, T. M., Park, S. H., Kwon, Y. M., Crandall, P. G., et al. (2016). An Overview of Salmonella Thermal Destruction during Food Processing and Preparation. Food Control 68, 280-290. doi:10.1016/j.foodcont. 2016.04.006

Jia, C., and Jukes, D. (2013). The National Food Safety Control System of China - A Systematic Review. Food control 32 (1), 236-245. doi:10.1016/j.foodcont.2012. 11.042

Joshi, L., and Prakash, R. (2013). Synthesis of Conducting Poly(5-Carboxyindole)/ $\mathrm{Au}$ Nanocomposite: Investigation of Structural and Nanoscale Electrical Properties. Thin solid films 534, 120-125. doi:10.1016/j.tsf.2013.02.025

Kang, D., Ricci, F., White, R. J., and Plaxco, K. W. (2016). Survey of Redox-Active Moieties for Application in Multiplexed Electrochemical Biosensors. Anal. Chem. 88 (21), 10452-10458. doi:10.1021/acs.analchem.6b02376

Kumar, T. H. V., and Sundramoorthy, A. K. (2019). Electrochemical Biosensor for Methyl Parathion Based on Single-Walled Carbon Nanotube/Glutaraldehyde Crosslinked Acetylcholinesterase-Wrapped Bovine Serum Albumin
Nanocomposites. Analytica Chim. Acta 1074, 131-141. doi:10.1016/j.aca. 2019.05.011

Law, J. W.-F., Ab Mutalib, N.-S., Chan, K.-G., and Lee, L.-H. (2015). Rapid Methods for the Detection of Foodborne Bacterial Pathogens: Principles, Applications, Advantages and Limitations. Front. Microbiol. 5, 770. doi:10. 3389/fmicb.2014.00770

Li, J., Wang, W., Liu, J., Li, H., Zhang, N., Yang, F., et al. (2021). Human-Like Performance Umami Electrochemical Biosensor by Utilizing CoElectrodeposition of Ligand Binding Domain T1R1-VFT and Prussian Blue. Biosens. Bioelectron. 193, 113627. doi:10.1016/j.bios.2021.113627

Liu, H., Zhen, S., Ming, S., Lin, K., Gu, H., Zhao, Y., et al. (2016). Furan and Pyridinechalcogenodiazole-Based $\pi$-Conjugated Systems via a Donor-Acceptor Approach. J. Solid State. Electrochem. 20 (8), 2337-2349. doi:10.1007/s10008016-3253-0

Narang, J., Chauhan, N., Rani, P., and Pundir, C. S. (2013). Construction of an Amperometric TG Biosensor Based on AuPPy Nanocomposite and Poly (Indole-5-Carboxylic Acid) Modified Au Electrode. Bioproc. Biosyst Eng 36 (4), 425-432. doi:10.1007/s00449-012-0799-9

Odeyemi, O. A., Alegbeleye, O. O., Strateva, M., and Stratev, D. (2020). Understanding Spoilage Microbial Community and Spoilage Mechanisms in Foods of Animal Origin. Compr. Rev. Food Sci. Food Saf. 19 (2), 311-331. doi:10.1111/1541-4337.12526

Pandey, A., Gurbuz, Y., Ozguz, V., Niazi, J. H., and Qureshi, A. (2017). GrapheneInterfaced Electrical Biosensor for Label-Free and Sensitive Detection of Foodborne Pathogenic E. C O157:H7. Biosens. Bioelectron. 91, 225-231. doi:10.1016/j.bios.2016.12.041

Park, J. Y., Park, K., Ok, G., Chang, H.-J., Park, T. J., Choi, S.-W., et al. (2020). Detection of Escherichia C O157:H7 Using Automated Immunomagnetic Separation and Enzyme-Based Colorimetric Assay. Sensors 20 (5), 1395. doi:10.3390/s20051395

Patra, J., and Baek, K.-H. (2016). Antibacterial Activity and Action Mechanism of the Essential Oil from Enteromorpha Linza L. Against Foodborne Pathogenic Bacteria. Molecules 21 (3), 388. doi:10.3390/molecules21030388

Qaanei, M., Taheri, R. A., and Eskandari, K. (2021). Electrochemical Aptasensor for Escherichia C O157: H7 Bacteria Detection Using a Nanocomposite of Reduced Graphene Oxide, Gold Nanoparticles and Polyvinyl Alcohol. Anal. Methods 13, 3101-3109. doi:10.1039/d1ay00563d

Rad, A. H., Aghebati-Maleki, L., Kafil, H. S., Gilani, N., Abbasi, A., and Khani, N. (2021). Postbiotics, as Dynamic Biomolecules, and Their Promising Role in Promoting Food Safety. Biointerface Res. Appl. Chem. 11 (6), 14529-14544. doi:10.33263/briac116.1452914544

Sai-Anand, G., Sivanesan, A., Benzigar, M. R., Singh, G., Gopalan, A.-I., Baskar, A. V., et al. (2019). Recent Progress on the Sensing of Pathogenic Bacteria Using Advanced Nanostructures. Bull. Chem. Soc. Jpn. 92 (1), 216-244. doi:10.1246/ bcsj. 20180280

Shi, J., Chan, C., Pang, Y., Ye, W., Tian, F., Lyu, J., et al. (2015). A Fluorescence Resonance Energy Transfer (FRET) Biosensor Based on Graphene Quantum Dots (GQDs) and Gold Nanoparticles (AuNPs) for the Detection of mecA Gene Sequence of Staphylococcus A. Biosens. Bioelectron. 67, 595-600. doi:10.1016/j. bios.2014.09.059

Sieuwerts, S., De Bok, F. A. M., Mols, E., De Vos, W. M., and van Hylckama Vlieg, J. E. T. (2008). A Simple and Fast Method for Determining Colony Forming Units. Lett. Appl. Microbiol. 47 (4), 275-278. doi:10.1111/j.1472-765x.2008. 02417.x

Sivakkumar, S. R., Angulakshmi, N., and Saraswathi, R. (2005). Characterization of Poly(indole-5-Carboxylic Acid) in Aqueous Rechargeable Cells. J. Appl. Polym. Sci. 98 (2), 917-922. doi:10.1002/app.22202

Sperber, W. H., North American Millers' Association Microbiology Working Group (2007). Role of Microbiological Guidelines in the Production and Commercial Use of Milled Cereal Grains: a Practical Approach for the 21st century. J. Food Prot. 70 (4), 1041-1053. doi:10.4315/0362-028x-70.4.1041

Stockman, J. A. (2013). German Outbreak of Escherichia Coli O104:H4 Associated with Sprouts. Yearb. Pediatr. 2013, 287-289. doi:10.1016/j.yped.2011.12.017

Xue, L., Huang, F., Hao, L., Cai, G., Zheng, L., Li, Y., et al. (2020). A Sensitive Immunoassay for Simultaneous Detection of Foodborne Pathogens Using $\mathrm{MnO} 2$ Nanoflowers-Assisted Loading and Release of Quantum Dots. Food Chem. 322, 126719. doi:10.1016/j.foodchem.2020.126719 
Yang, T., Ren, X., Yang, M., Li, X., He, K., Rao, A., et al. (2019). A Highly Sensitive Label-Free Electrochemical Immunosensor Based on Poly(Indole-5-Carboxylicacid) with UltraHigh Redox Stability. Biosens. Bioelectron. 141, 111406. doi:10.1016/j.bios.2019.111406

Yang, T., Yang, X., Guo, X., Fu, S., Zheng, J., Chen, S., et al. (2020). A Novel Fluorometric Aptasensor Based on Carbon Nanocomposite for Sensitive Detection of Escherichia C O157:H7 in Milk. J. Dairy Sci. 103 (9), 7879-7889. doi:10.3168/jds.2020-18344

Yang, Q., Deng, S., Xu, J., Farooq, U., Yang, T., Chen, W., et al. (2021). Poly (Indole-5-Carboxylic Acid)/Reduced Graphene Oxide/gold Nanoparticles/ Phage-Based Electrochemical Biosensor for Highly Specific Detection of Yersinia Pseudotuberculosis. Microchimica Acta 188 (4), 1-13. doi:10.1007/ s00604-020-04676-y

Yao, L., Zheng, L., Cai, G., Wang, S., Wang, L., and Lin, J. (2020). A Rapid and Sensitive Salmonella Biosensor Based on Viscoelastic Inertial Microfluidics. Sensors 20 (9), 2738. doi:10.3390/s20092738

Zhao, X., Lin, C.-W., Wang, J., and Oh, D. H. (2014). Advances in Rapid Detection Methods for Foodborne Pathogens. J. Microbiol. Biotechnol. 24 (3), 297-312. doi: $10.4014 /$ jmb.1310.10013

Zhao, L., Guo, J., Li, S., and Wang, J. (2021). The Development of Thermal Immunosensing for the Detection of Food-Borne Pathogens E. coli O157: H7 Based on the Novel Substoichiometric Photothermal Conversion Materials MoO3X NPs. Sensors Actuators B: Chem. 344, 130306. doi:10.1016/j.snb.2021.130306
Zhou, B., Ye, Q., Chen, M., Li, F., Xiang, X., Shang, Y., et al. (2022). Novel SpeciesSpecific Targets for Real-Time PCR Detection of Four Common Pathogenic Staphylococcus Spp. Food Control 131, 108478. doi:10.1016/j.foodcont.2021. 108478

Conflict of Interest: The authors declare that the research was conducted in the absence of any commercial or financial relationships that could be construed as a potential conflict of interest.

Publisher's Note: All claims expressed in this article are solely those of the authors and do not necessarily represent those of their affiliated organizations, or those of the publisher, the editors, and the reviewers. Any product that may be evaluated in this article, or claim that may be made by its manufacturer, is not guaranteed or endorsed by the publisher.

Copyright (c) 2022 Wang, Fan, Yang, Sun, Liu, Chen, Aziz and Wang. This is an open-access article distributed under the terms of the Creative Commons Attribution License (CC BY). The use, distribution or reproduction in other forums is permitted, provided the original author(s) and the copyright owner(s) are credited and that the original publication in this journal is cited, in accordance with accepted academic practice. No use, distribution or reproduction is permitted which does not comply with these terms. 